\title{
Field validation of radon monitoring as a screening methodology for NAPL-contaminated sites
}

\author{
J.E. García-González, M.F. Ortega, E. Chacón, L.F. Mazadiego, E. De Miguel \\ Grupo de Geoquímica Ambiental, Universidad Politécnica de Madrid, E.T.S. Ingenieros de Minas, Alenza 4, 28003 Madrid, Spain
}

\begin{abstract}
A B S T R A C T
Screening methodologies aim at improving knowledge about subsurface contamination processes before expensive intrusive operations, i.e. drilling and core-sampling, well installation and development, sampling of groundwater and free-phase product, are implemented. Blind field tests carried out at a hydrocarbon storage and distribution center in NE Spain suggest that Rn monitoring can be effectively used to locate the boundaries of subsurface accumulations of NAPLs. Sixty seven measurements of Rn in soil air were performed with a SARAD RTM 2100 current-ionization alpha-particle spectrometer following a $10 \mathrm{~m}$ square grid. Reductions of ${ }^{222} \mathrm{Rn}$ concentration above a pool of LNAPL due to the preferential partition of Rn into the organic phase were spatially analyzed and resolved to yield the surface contour of the NAPL source zone. This surface trace of the source zone agreed well with the extent and situation inferred from measurements of free-phase thickness taken at eight monitoring wells at the site. Moreover, the good repeatability (as measured by replicate measurements at the same sampling point) and spatial resolution of the technique suggest that the boundaries of the plume can be delineated at the sub-decametre level.
\end{abstract}

\section{Introduction}

The task of locating and quantifying the amount of non-aqueous phase liquids (NAPLs) present in the subsurface at contaminated waste or industrial sites has presented significant challenges to date. Traditionally, this has been done by drilling and core-sampling the vadose zone and by installing wells to collect samples of groundwater and free-phase products, if present. Drilling, coring, pumping, preserving, transporting and analyzing solid and liquid samples are all expensive operations. If preliminary information regarding the location of the source zone and of the plume of contaminants is lacking or is insufficient, there is a clear risk that time and money will be wasted in drilling and installing wells in the wrong locations, where they will yield useless or misleading data.
The difficulties with conventional methods have prompted the development of innovative techniques, like partitioning and interfacial tracers, or the adaptation of already existing non-invasive, surface techniques, i.e. soil vapor analysis, geophysical methods and Rn measurements (emanometry), to estimate the location, amount and interfacial area of NAPLs in the vadose and saturated zones. Emanometry has the advantage that it can locate and determine the boundaries of free-phase plumes of contaminants even when the amount of organic vapors reaching the surface is very low or non-existent. This can be the case if the mixture of NAPLs has a low content of volatile components, if the pool of NAPLs is located at a great depth, or if it lies beneath the groundwater table.

The purpose of this study is to evaluate under real field conditions whether the repetibility, spatial resolution and operational aspects of emanometry make it a time- and cost-efficient in situ tool to deterministically delineate the surface trace of sub-surface NAPL accumulations. 


\subsection{Physico-chemical background}

Radon in soil air in the vadose zone can have a deep origin or it can be generated in the saturated and vadose zones as the decay product of Ra within the decay series of $U$ and Th. The flux of Rn from the subsurface towards the atmosphere and its variations have been extensively used in prospecting campaigns for $U$ deposits (Sutton and Soonawala, 1975), as indicators of seismic, geothermal and volcanic activity (Fleischer and Mogro-Campero, 1985; Gasparini and Mantovani, 1978; Nielson, 1978; Virk et al., 2000) and in the characterization of subsurface fracture systems (Gascoyne et al., 1992). In terms of its applicability to detect the presence of hydrocarbons in the subsurface, Rn monitoring can be viewed as a technique that makes a two-fold use of natural tracers - U/Ra - to localize and delimit the extent of subsurface hydrocarbon accumulations.

In geochemical prospecting for petroleum deposits, the presence of hydrocarbons in the subsurface produces a reducing environment around the area where they accumulate. This reducing environment causes the uranyl ion $\left(\mathrm{UO}_{2}^{2+}\right)$ dissolved in groundwater to reduce from $\mathrm{a}+6$ to $\mathrm{a}+4$ oxidation state and to precipitate as $\mathrm{UO}_{2}$ around the pool of hydrocarbons. The most likely chemical mechanisms for this process are

$$
\begin{aligned}
& 3 \mathrm{UO}_{2}^{2+}+\mathrm{CH}_{4}+\mathrm{H}_{2} \mathrm{O} \rightarrow \mathrm{CO}+3 \mathrm{UO}_{2}+6 \mathrm{H}^{+} \\
& 4 \mathrm{UO}_{2}^{2+}+\mathrm{CH}_{4}+2 \mathrm{H}_{2} \mathrm{O} \rightarrow \mathrm{CO}_{2}+4 \mathrm{UO}_{2}+8 \mathrm{H}^{+}
\end{aligned}
$$

A halo of precipitated $U$ will form around the hydrocarbon pool where it will start disintegrating and become a source of Rn gas. This Rn gas migrates upwards to the ground surface where it can be registered as higher-thanbackground signals that mark the contour of the subsurface NAPL accumulation (Mazadiego, 1994; Morse et al., 1982).

The applicability of Rn monitoring to the task of locating and delineating the surface trace of subsurface contaminant plumes is based on the fact that ${ }^{226} \mathrm{Ra}$ - as a decay product of ${ }^{238} \mathrm{U}$ - which is naturally present in the solid matrix of aquifers gives rise to a flux of ${ }^{222} \mathrm{Rn}$ towards the air or water phase occupying the void space between mineral grains. The activity of ${ }^{222} \mathrm{Rn}$ in the water phase reaches an equilibrium (emanation-decomposition) which is dictated by the aquifer's mineral matrix. However, if the groundwater comes into contact with a NAPL pool the activity of ${ }^{222} \mathrm{Rn}$ is significantly reduced due to the preferential partition of Rn into the organic phase (Höhener and Surbeck, 2004). The solubility of Rn gas in pure organic phases is well established (Clever, 1979). Schubert et al. (2002, 2007a) carried out laboratory experiments to determine the partition coefficients $K_{\mathrm{NAPL} / \mathrm{W}}$ and $K_{\mathrm{NAPL} / \mathrm{AIR}}$ for commercial mixtures of petroleum hydrocarbons (gasoline, diesel, kerosene) and demonstrated the ability of NAPL accumulations to act as geochemical traps for Rn. The resulting reduction in Rn activity in the soil air of the vadose zone should therefore indicate the presence of underlying levels with high hydrocarbon saturation (Hunkeler et al., 1997; Semprini et al., 2000; Schubert et al., 2001, 2002, 2005, 2007b). Field tests and laboratory experiments published by Schubert et al. (2007c), Fan et al. (2007), Davis et al., (2002, 2003) and Semprini et al. (2000) suggest that Rn can be used as a non-conservative tracer to estimate LNAPL saturation in the subsurface.

\section{Materials and methods}

Radon-222 measurements were performed between May and September 2007 under dry conditions (i.e. at least $48 \mathrm{~h}$ were allowed after the last precipitation) with a SAR$\mathrm{AD}^{\circledR} \mathrm{RTM} 2100$ radon monitor in which the daughter products of $\mathrm{Rn}\left({ }^{218} \mathrm{Po} /{ }^{214} \mathrm{Po}\right.$ and $\left.{ }^{216} \mathrm{Po}\right)$ are ionized and collected on the surface of a semiconductor detector. The subsequent radioactive decay of these isotopes is registered with a multichannel analyzer (alpha-spectrometry). Integration time was set at $5 \mathrm{~min}$ and the measurements were carried out for 60-120 min depending on the sampling point. After each series of measurements, the internal pump was set at high flow ("thoron mode") for 20-30 min. to clean the ionization chamber before the next measurement was started. The Rn monitor was fitted with a canister filled with drierite $\left(97 \% \mathrm{CaSO}_{4}+3 \% \mathrm{CoCl}_{2}\right)$ and a hydrophobic Teflon ${ }^{\circledR}$ filter to keep humidity within the instrument at a minimum and to prevent fine particles from entering the ionization chamber. Soil air was collected with the help of a stainless-steel hollow probe which was hammered into the soil down to a depth of $75-100 \mathrm{~cm}$ in order to minimize the influence of atmospheric factors (Schubert et al., 2005). The bottom of the hollow probe was fitted with a stainless-steel lost tip. When the desired sampling depth was reached, the tip was pushed down with a stainless-steel rod inserted through the inner space of the hollow probe. A gap was thus created through which soil air could be pumped up the hollow probe and into the ionization chamber of the instrument. Where manual insertion of the probe was impractical, an electric drilling hammer was used to penetrate past the obstacles and the hollow probe was then further hammered to the desired depth.

Atmospheric variables, i.e. temperature, barometric pressure, air relative humidity and wind strength were recorded during each measurement (Schubert and Schulz, 2002). To make all measurements comparable, at least $48 \mathrm{~h}$ were allowed to pass after any precipitation had ceased before any measurement was performed so as to minimize variations of soil moisture content and consequently of Rn emanation from the soil matrix. Water and free-phase levels were registered in all available monitoring wells with an interface probe and measurements of volatile organic compounds (VOCs) were carried out with a photo-ionization detector (PID) both at monitoring wells and at several boreholes of the Rn sampling grid.

The site selected for this investigation is a $120,000 \mathrm{~m}^{2}$ gasoline, diesel oil and fuel storage and distribution center which has been operating since 1898 . The plant is located approximately $500 \mathrm{~m}$ north of the coast line and $40 \mathrm{~m}$ to the west and north of a small river in north-eastern Spain. The soil profile at the site is dominated by the gravel, sand and silty clay that constitute the most recent quaternary terrace of the river. The depth of the water table beneath the plant is approximately $4 \mathrm{~m}$ although it fluctuates 
significantly, and the groundwater flows in a southerly direction.

The monitoring campaign was limited to the southwestern sector of the plant where a $30-70 \mathrm{~cm}$ thick top layer of heterogeneous backfill materials is underlain by $1.5-3 \mathrm{~m}$ of sandy silt and silty clay with carbonaceous nodules, followed by gravel and sand with varying degrees of cementation, and brownish-grey fine sand down to the maximum depth reached in the boreholes at the site (Fig. 1). Light free product was detected in several of those boreholes, probably as a consequence of historic spills and recent leaks from nearby tanks. Data on thickness or absence of the NAPL layer was not made available until after the Rn monitoring campaign had been completed. Instead the sampling campaign followed an adaptive design in which the information from previous measurements was used to decide which point in the pre-established grid would be sampled next.

\section{Results and discussion}

A total of 67 measurements were carried out on a $10 \mathrm{~m}$ square grid during five weeks in the summer of 2007 . The measurement series registered at each sampling point was reduced to a single value for the spatial interpretation of the data. To that end a two-parameter non-linear model (Eq. (1)) was used to extrapolate the equilibrium concentration of $\mathrm{Rn}$ in soil air at $t=\infty$ (i.e. $\beta_{0}$ ) with the data registered at each point in the grid

$C(t)=\beta_{0} \times\left(1-\mathrm{e}^{\frac{-t}{\beta_{1}}}\right)$

Equation 1: Non-linear model used to extrapolate the concentration of ${ }^{222} \mathrm{Rn}$ in soil air.

A $195 \mathrm{~min}$ measurement series was used to evaluate the goodness of fit of the model for different measurement durations. Table 1 presents the results for 9, 12, 18 and 24 recorded values (i.e. $45,60,90$ and $120 \mathrm{~min}$, respectively) as well as for $t=\infty$. Since the standard error of $\beta_{0}$ falls from $27 \%$ to $16 \%$ and the length of the confidence interval decreases from $105,000 \mathrm{~Bq} \mathrm{~m}^{-3}$ to $20,700 \mathrm{~Bq} \mathrm{~m}^{-3}$ between the 45 and 60 min models, $60 \mathrm{~min}$ seems to be a reasonable minimum length of time for a valid measurement. On the few occasions when the residual concentration from a previous measurement was so high that the model would not yield a valid $\beta_{0}$, the measurement was repeated after the monitor had been cleaned for a sufficiently long time.

Radon concentrations obtained in this way ranged from 1900 to $36,000 \mathrm{~Bq} \mathrm{~m}^{-3}$, with minimum values to the North - near monitoring well P 09 - and maximum values to the

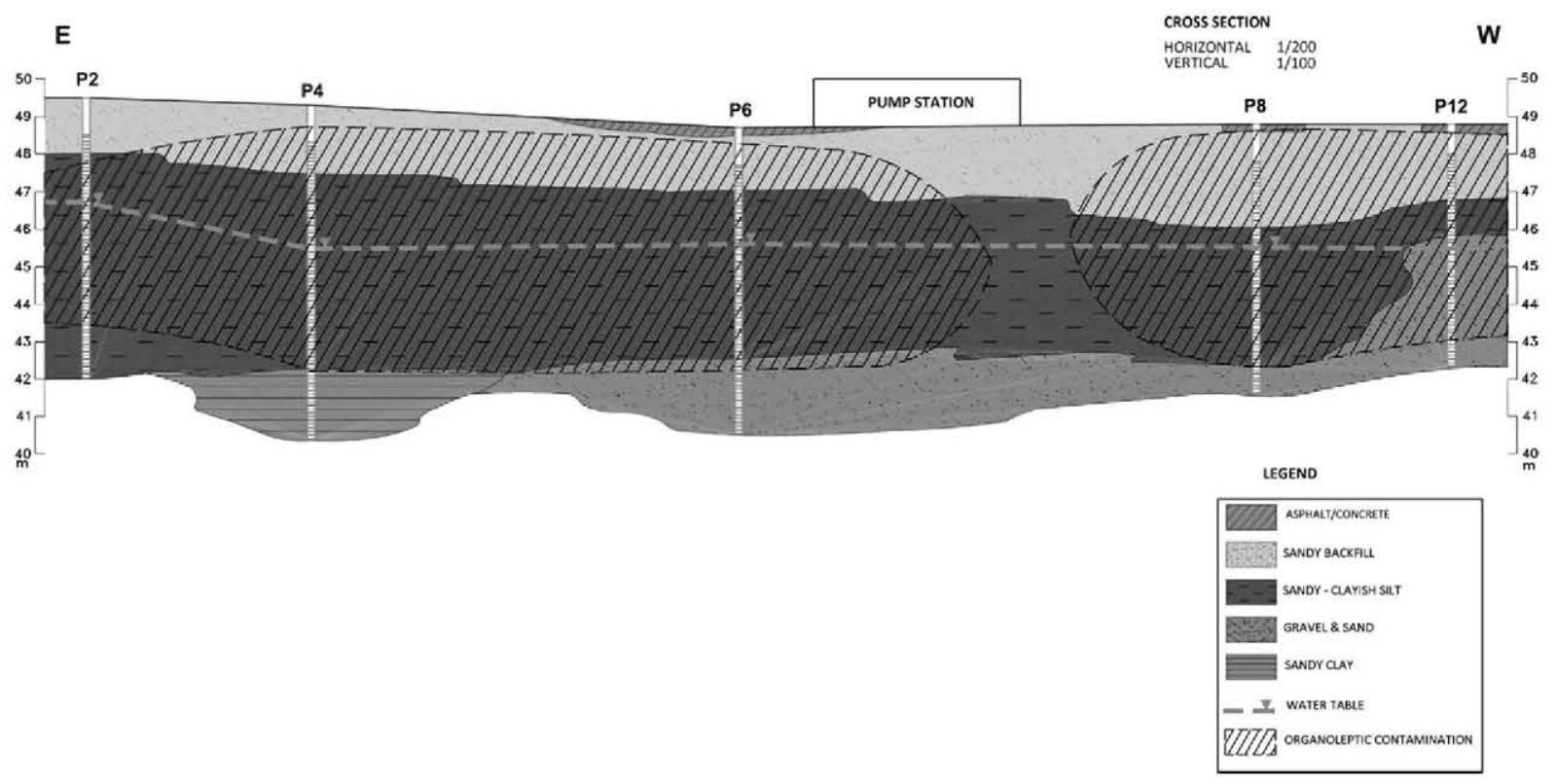

Fig. 1. Geological cross-section of the study-site.

Table 1

Standard error (std. err.), and lower and upper limits of the $95 \%$ confidence interval for $\beta_{0}$ and $\beta_{1}\left(\beta_{01}, \beta_{0 u}, \beta_{11}, \beta_{1 u}\right)$ for measurement series lasting $45,60,90,120$ and $\infty$ minutes ("Model")

\begin{tabular}{|c|c|c|c|c|c|c|c|c|}
\hline Model & $\beta_{0}$ & Std. err. & $\beta_{1}$ & Std. err. & $\beta_{\text {OI }}$ & $\beta_{\text {Ou }}$ & $\beta_{11}$ & $\beta_{1 \mathrm{u}}$ \\
\hline 45 & 18193.62 & 4842.26 & 38.88 & 16.10 & 12993.30 & 118099.22 & 21.76 & 336.19 \\
\hline 60 & 19975.00 & 3318.62 & 44.87 & 12.29 & 15411.91 & 36112.39 & 27.89 & 103.76 \\
\hline 90 & 20325.60 & 1213.03 & 46.36 & 5.52 & 18169.00 & 23584.86 & 36.53 & 61.14 \\
\hline 120 & 20777.78 & 745.51 & 48.12 & 4.03 & 19390.22 & 22557.15 & 40.65 & 57.74 \\
\hline$\infty$ & 22281.53 & 393.98 & 55.10 & 2.89 & 21517.08 & 23137.78 & 49.52 & 61.44 \\
\hline
\end{tabular}


South and West of the study area. The halo of maximum values (dark colours in Graph B, Fig. 2) is quite uniform except at the western border of the study area, due to the absence of measured data in that sector - and encloses a cluster of low values that follow the direction of groundwater flow (dotted line from $A^{\prime}$ to A, Graph B, Fig. 2). The sampling grid is not extensive enough to follow the expected succession of maximum values to the east and thus no inferences can be made about the boundaries of the free-phase plume in that direction.

Data from 8 monitoring wells were used to independently estimate the location of the subsurface plume of free product. Although a larger number of boreholes could have reduced the uncertainty in the delineation of the plume's boundaries, it is clear that the free product is advancing in a south-westernly direction and that it has not yet reached the south-western most monitoring well (Graph A, Fig. 2). Despite the uncertainty associated with the map of free-product thickness, there is a remarkable coincidence between the halo of $\mathrm{Rn}$ maximum values (Graph B, Fig. 2) and the inferred front of the advancing plume. The inverse relationship between thickness of free product in the subsurface and concentration of $\mathrm{Rn}$ in soil air is clearly shown in Fig. 3, where the values of both variables along transect $A^{\prime}-A$, following groundwater flow direction, are plotted together.

Six series of replicates separated by less than $0.5 \mathrm{~m}$ were carried out at 1 day intervals at the site to assess the repeatability of the method. The degree of agreement between replicate values measured by the relative standard deviation ranged between $6 \%$ and $28 \%$, for 5 of the 6 series and it was $56 \%$ in the sixth (Table 2). The spatial resolution of the technique was evaluated with two transects

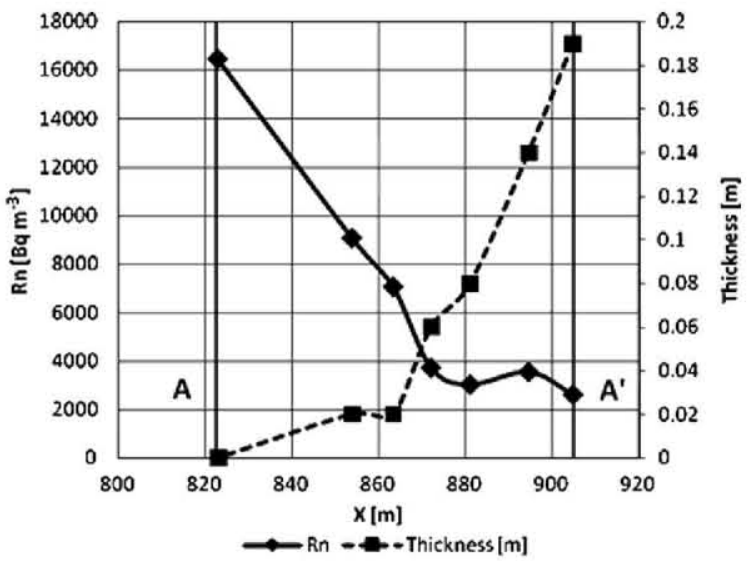

Fig. 3. Evolution of ${ }^{222} \mathrm{Rn}$ in soil air and inferred thickness of NAPL layer following groundwater flow direction along transect $A-A^{\prime}$ (shown in Fig. 1).

of 4 measurements performed at $3 \mathrm{~m}$ intervals over what appeared in the field to be the edge of the plume. The results showed a significant increase in each measurement relative to the previous one towards the outer side of the edge, except between the second and third point in transect 1 (Fig. 4). These results suggest that changes in the thickness of the free-product layer and the presence or absence of it, i.e. the boundary of the NAPL plume, can be detected on a sub-decametre scale.

Despite the ease of use, time and cost efficiency, and good resolution and repeatability of emanometry, some of its limitations have also become manifest during these field tests. Firstly, when there is high water saturation in

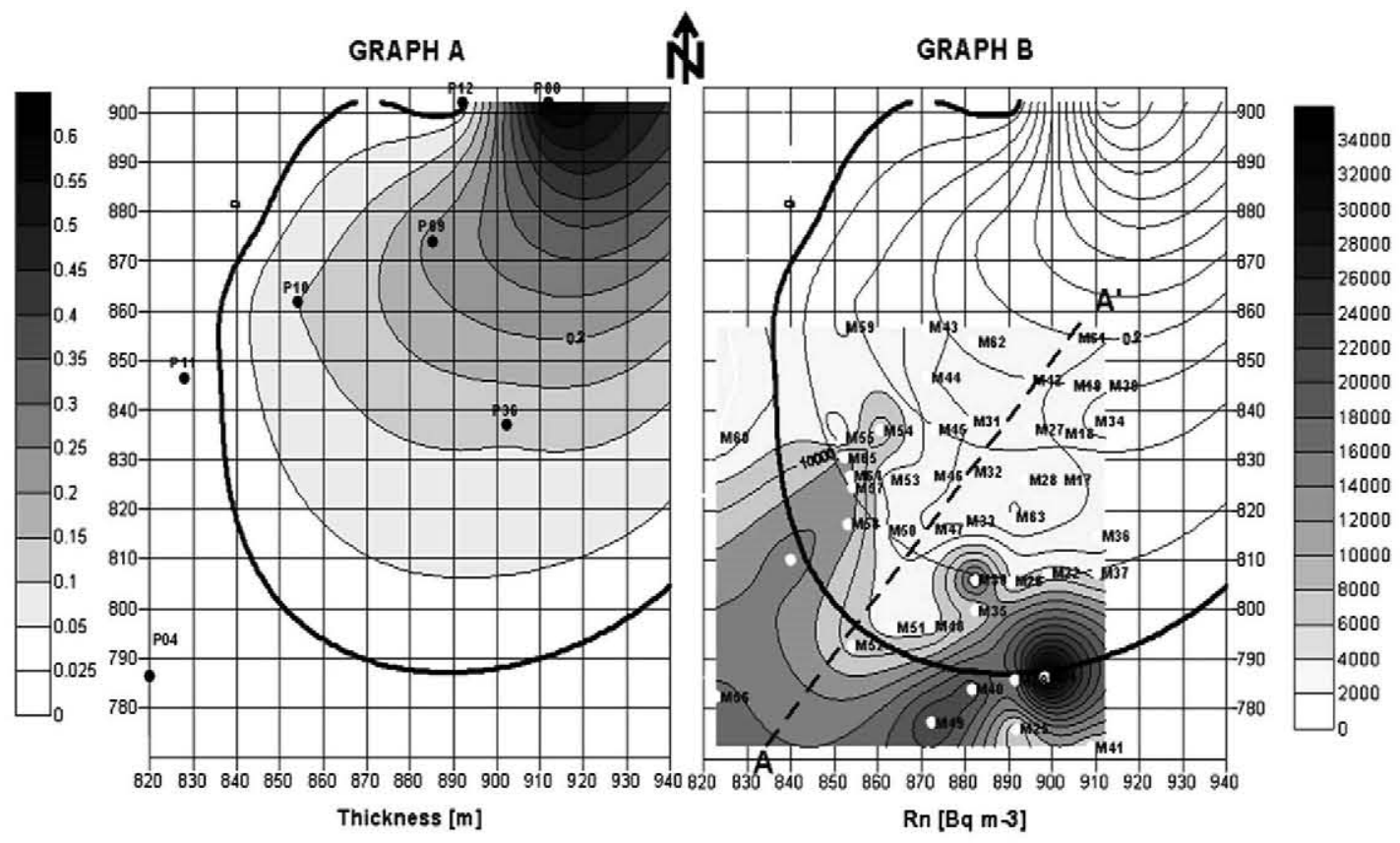

Fig. 2. Inferred sub-surface NAPL distribution and location of monitoring wells (Graph A) and distribution pattern of Rn in soil air (Graph B) (iso-curves of NAPL thickness and estimated front of NAPL plume in Graph A are superimposed on Graph B for comparison purposes). 
Table 2

Repeatability of the method as ealuated by the relative standard deviation of replicate measurements at 1 day intervals (std. dev.: standard deviation; rel. std. dev.: relative standard deviation)

\begin{tabular}{|c|c|c|c|}
\hline Sample & ${ }^{222} \mathrm{Rn}\left(\mathrm{Bq} \mathrm{m}^{-3}\right)$ & Std. dev. & Rel. std. dev. \\
\hline M18R & 4245 & & \\
\hline M18RR & 4523 & & \\
\hline M18RRR & 4856 & & \\
\hline M18RRRR & 4587 & 251 & 0.06 \\
\hline M29R & 14,376 & & \\
\hline M29RR & 17,547 & & \\
\hline M29RRR & 17,236 & 1748 & 0.11 \\
\hline M38R & 3108 & & \\
\hline M38RR & 7187 & 2885 & 0.56 \\
\hline M49R & 14,985 & & \\
\hline M49RR & 22,282 & 5159 & 0.28 \\
\hline M54R & 8882 & & \\
\hline M54RR & 11,766 & & \\
\hline M54RRR & 15,645 & & \\
\hline M54RRRR & 14,992 & 2077 & 0.15 \\
\hline M76R & 3557 & & \\
\hline M76RR & 2622 & 661 & 0.21 \\
\hline M77R & 5187 & & \\
\hline M77RR & 3702 & 1050 & 0.24 \\
\hline
\end{tabular}

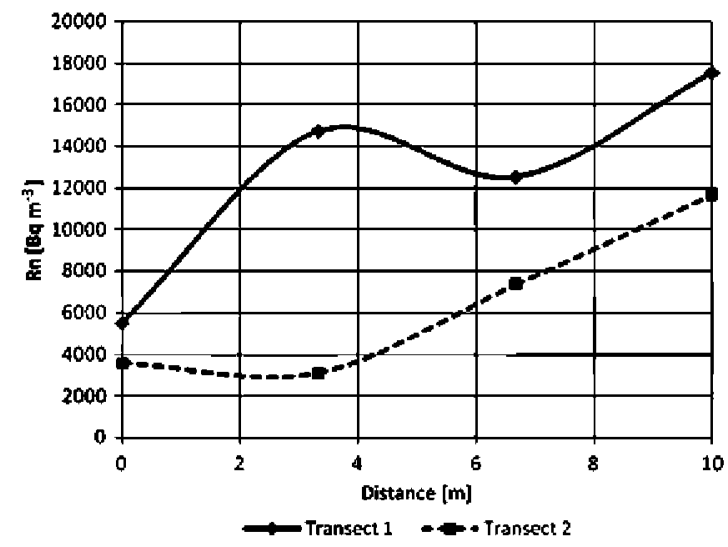

Fig. 4. Differences between successive measurements at $3 \mathrm{~m}$ intervals along two transects at the edge of the plume (first and last points in both transects belong to the $10 \mathrm{~m}$ regular grid).

the vadose zone or a shallow water table, care should be taken to use a large enough volume of drierite to keep humidity in the ionization chamber at the minimum levels required for a reliable determination with current-ionization spectrometers like the one used in this study. Another important limitation arises from the need to draw the soil air sample at a depth of at least $70 \mathrm{~cm}$ in order to minimise the influence of atmospheric variables on the measured $\mathrm{Rn}$ concentration. Insertion of a hollow probe down to those depths may not be possible in heterogeneous soils or in the presence of thick clay lenses, and may have to be completely ruled out if there is underground infrastructure like electrical wiring, product pipes, etc.

\section{Conclusions}

Although the estimate of the background value at the site was based on repeated measurements at just one point, and is therefore affected by a significant uncertainty, the results of this study seem to corroborate that, as was theoretically predicted, reductions of Rn concentration in soil air above subsurface accumulations of hydrocarbons can be deterministically differentiated from background values (the former being between 5 and 10 times lower than the latter) under real field conditions.

The repeatability of the method, with replicate measurements agreeing within a standard error of the mean of $30 \%$ for most cases and its spatial resolution on the sub-decametre level make in situ Rn monitoring suitable to not only locate free-phase plumes of LNAPLs but also to determine the surface trace of their boundaries with enough accuracy for the purposes of site assessment and site remediation.

The confounding influence of fluctuating climatic parameters can be minimized to levels within the measurement error of the instrument by drawing soil air at a depth of approximately $1 \mathrm{~m}$ (Schubert and Schulz, 2002). The influence of soil humidity, however, may be large enough to invalidate the Rn measurement when the water table lies near the depth at which soil air is collected, even if the soil air is circulated through hydrophobic materials and filters.

In terms of time efficiency, measurement times can be significantly shortened, without loss of accuracy, by using mathematical algorithms to infer the equilibrium concentration. Even so, Rn measurements - including cleaning times - will still take longer to complete than direct soil gas measurements (i.e. PID, FID, etc.) but are less sensitive to changes in subsurface properties and are still applicable for contaminants with low vapor pressure.

\section{Acknowledgements}

The authors would like to thank the Spanish Ministry of Environment for their support of this research project through Grant 144/2006/2-1.2. The authors are also very much indebted to Dr. Michael Schubert and a second anonymous reviewer for their helpful comments which have greatly improved the quality of the original manuscript.

\section{References}

Clever, H.L. (Ed.), 1979. Krypton, Xenon, and Radon: Gas Solubilities Solubility Data Series. Pergamon Press, New York. vol. 2.

Davis, B.M., Istok, J.D., Semprini, L., 2002. Push-pull partitioning tracer tests using radon-222 to quantify non-aqueous phase liquid contamination. J. Contam. Hydrol. 58, 129-146.

Davis, B.M., Istok, J.D., Semprini, L., 2003. Static and push-pull methods using radon-222 to characterize dense nonaqueous phase liquid saturations. Groundwater 41, 470-481.

Fan, K., Kuo, T., Han, Y., Chen, C., Lin, C., Lee, C., 2007. Radon distribution in a gasoline -contaminated aquifer. Radiat. Meas. 42, 479-485.

Fleischer, R.L., Mogro-Campero, A., 1985. Association of subsurface radon changes in Alaska and the north-eastern United States with earthquakes. Geochim. Cosmochim. Acta 49, 1061-1071.

Gascoyne, M., Wuschke, D.M., Durrance, E.M., 1992. Fracture detection and groundwater flow characterisation using $\mathrm{He}$ and $\mathrm{Rn}$ soil gases, Manitoba, Canada. Appl. Geochem. 8, 223-233.

Gasparini, P., Mantovani, M.S., 1978. Radon anomalies and volcanic eruptions. J. Volcanol. Geotherm. Res. 3, 325-341.

Höhener, P., Surbeck, H., 2004. Radon-222 as a tracer for nonaqueous phase liquid in the vadose zone: experiments and analytical model. Vadose Zone J. 3, 1276-1285. 
Hunkeler, D., Hoehn, E., Höhener, P., Zeyer, J., 1997. ${ }^{222}$ Rn as a partitioning tracer to detect diesel fuel contamination in aquifers: laboratory study and field observations. Environ. Sci. Technol. 31, 3180-3187.

Mazadiego, L.F., 1994. Desarrollo de una metodología para la prospección geoquímica en superficie de combustibles fósiles. Ph.D. Thesis, Polytechnic Univ. Madrid.

Morse, J.G., Rana, M.H., Morse, L., 1982. Radon mapping as indicators of subsurface oil and gas. Oil Gas J. 80, 227-246.

Nielson, D.L., 1978. Radon emanometry as a geothermal exploration technique: theory and an example from Roosevelt Hot Springs KGRA Utah. Earth Science Laboratory, University of Utah Research Institute. <http://www.ostigov/energycitations/servlets/purl/5815672-WhNZCO/ native/5815672.pdf>

Schubert, M., Schulz, H., 2002. Diurnal radon variations in the upper soil layers and at the soil-air interface related to meteorological parameters. Health Phys. 83, 91-96.

Schubert, M., Balcázar, M., Lopez, A., Peña, P., Flores, J.H., Knöller, K., $2007 \mathrm{c}$. Combination of radon and stable isotope analysis as tool for decision support concerning the remediation of NAPL contaminated sites. Isot. Environ. Health S 43, 215-226.

Schubert, M., Freyer, K., Treutler, H.C., Weiß, H., 2001. Using soil gas radon as an indicator for ground contamination by non-aqueous phaseliquids. J. Soil Sediment. 1, 217-222.
Schubert, M., Freyer, K., Treutler, H.C., Weiß, H., 2002. Using radon-222 in soil gas as an indicator of subsurface contamination by non-aqueous phase liquids (NAPLs). Geofísica Int. 41, 433-437.

Schubert, M., Lehman, K., Paschke, A., 2007a. Determination of radon partition coefficients between water and organic liquids and their utilization for the assessment of subsurface NAPL contamination. Sci. Total Environ. 376, 306-316.

Schubert, M., Paschke, A., Lau, S., Meissner, R., Geyer, W., Knöller, K., $2007 \mathrm{~b}$. Radon as a naturally occurring tracer for the assessment residual NAPL contamination of aquifers. Environ. Pollut. 145, 920927.

Schubert, M., Pena, P., Balcazar, M., Meissner, R., Lopez, A., Flores, J.H. 2005. Determination of radon distribution patterns in the upper soil as a tool for the localization of subsurface NAPL contamination. Radiat. Meas. 40, 633-637.

Semprini, L., Hopkins, O.S., Tasker, B.R., 2000. Laboratory, field and modeling studies of Radon-222 as a natural tracer for monitoring NAPL contamination. Transp. Porous Med. 38, 223-240.

Sutton, W.R., Soonawala, N.M., 1975. A soil radium method for uranium prospecting. Can. Min. Metall. Bull. 68, 51-56.

Virk, H.S., Walia, V., Sharma, A.K., Kumar, N., Kumar, R, 2000. Correlation of radon anomalies with microseismic events in Kangra and Chamba valleys of N-W Himalaya. Geofísica Int. 39, 221-227. 